\title{
EXPERIENCE IN THE SUCCESSFUL MANAGEMENT OF EIGHT CASES OF CONGENITAL VAGINAL SEPTA
}

\begin{tabular}{ll} 
Dr. K. Anji Reddy* & Director and professor of Plastic Surgery. ${ }^{*}$ Corresponding Author \\
\hline Dr. Srilakshmi & M.S, Associate Professor of Department of OBGY. \\
\hline Dr. K. Vandana & M.S, Professor \& HOD of Department of OBGY. \\
\hline $\begin{array}{l}\text { Dr. K. Prasanna } \\
\text { lakshmi }\end{array}$ & MBBS, Postgraduate of Department of OBGY. \\
\hline
\end{tabular}

ABSTRACT

Background: Vaginal septum is a rare congenital abnormality of the female genital tract. It can be asymptomatic or may be present with a variety of symptoms like amenorrhea, dyspareunia, dysmenorrhea, infertility and abortions.

Aims And Objectives: To study patients with vaginal septum presenting at our hospital in detail with clinical findings investigations and their surgical management.

Materials And Methods: A prospective study of eight cases of vaginal septum diagnosed at ASRAM Medical College ,Eluru.

Results: All cases of transverse and longitudinal vaginal septum were successfully operated, had normal sexual life and menstrual cycles. They conceived and had children varying from one to three.

\section{KEYWORDS : Development of vagina, vaginal septa, primary amenorrhea, didelphys uterus, infertility.}

\section{INTRODUCTION:}

Development of vagina:

The lower ends of mullerian ducts terminate in posterior part of the urogenital sinus ${ }^{1}$, where they project as a solid Mullerian tubercle. A solid vaginal cord results from proliferation of cells at the caudal tip of fused Mullerian ducts ${ }^{2}$. The cord elongates to meet the bilateral endodennal evaginations (sinovaginal bulbs) from the posterior aspect of urogenital sinus below, and both fuse to form a vaginal plate ${ }^{3}$. Vagina is formed by subsequent canalisation of the vaginal cord followed by epithelialisation of the canal by cells derived from urogenital sinus ${ }^{4}$. Recent proposals hold that only the upper one-third of vagina is formed from Mullerian ducts and the lower vagina develops from the vaginal plate of the uroogenital sinus.

\section{Transverse vaginal septum:}

- Transverse vaginal septum, a vertical fusion disorder,is a rare congenital utero-vaginal anomaly (class II under the Rock and Adam classification) between mullerian ducts and urogenital sinus, which has been linked to autosomal recessive transmission ${ }^{5}$. It is unusal for pregnancy to occur when these malformations are present since many of them may cause infertility.

\section{Epidemiology}

- It is rare with a frequency of $l$ in 70,000 females.

- The patient presentation may vary from newborn to older adolescent girls. The septum may be complete or may present with a small opening allowing escape of menstrual blood.

- Transverse vaginal septum is composed of fibrous tissue and muscular component. They are classified depending on its distance from introitus as low $(<3 \mathrm{~cm})$, mid $(3-6 \mathrm{~cm})$ and high $(>6 \mathrm{~cm})$. According to its thickness it is categorised as thin $<1$ $\mathrm{cm}$, thick $>1 \mathrm{Cm}$ and as perforate or imperforate.

\section{Pathology}

-It is a type of vertical fusional defect. A transverse vaginal septum may be either perforate (incomplete) or imperforate (complete) and results from varying degrees of failure in resorption of the tissue between the vaginal plate and the caudal aspect of the fused mullerian ducts ${ }^{6}$.

\section{Āssociations}

- While it may occur in isolation it is often combined with other mullerian duct anomalies such as uterus didelphys ${ }^{7}$.

\section{Location - Position}

- It can occur at almost any level of the vagina. Reported prevalence in terms of position include

- High vaginal - $46 \%$

- Mid vaginal - $40 \%$

- Low vaginal - 14\%

\section{Clinical Presentation}

- In the case of a complete septum, patients commonly present with primary amenorrhoea and cyclic pelvic pain.

- It is unusal for pregnancy to occur when these malformations are present since many of them may cause infertility.

\section{TRANSVERSE VAGINAL SEPTUM IS OFTEN MISTAKEN FOR}

(A) Imperforate Hymen

(B) Primary Amenorrhoea with Vaginal Atresia as a result of Mullerian Ägenesis.

COMPLETE VAGINAL SEPTUM is often associated with: A) Primary amenorrhoea with cyclical lower abdominal pain B)On examination there can be Hematocolpos and /or Hematometra

INCOMPLETE TRANSVERSE SEPTUM is often associated with Apareunia or Dyspareunia or Dysmenorrhoea. .

- Important differential diagnosis of a high vaginal septum is absent cervix that can be diagnosed on MRI with reasonable accuracy . Another differential diagnosis of a low vaginal septum on MRI is an imperforate hymen which on examination presents as a bluish bulge which increases on valsalva maneuver.

\section{Treatment of Transverse Vaginal Septum}

Complete excision of the septum, drainage of hematocolpos and repair of vaginal mucous membrane with $3 / 0$ vicryl. To avoid stenosis a single $\mathrm{Z}$ - plasty may be incorporated in the anterior or posterior vaginal wall. In cases if the vaginal septum is thick as tension less repair of vaginal mucosa is not possible, skin grafting may be necessary with Mc Indoe technique to prevent further vaginal stenosis and associated problems. Furthermore postoperative vaginal dilatation is necessary to prevent narrowing and stenosis of vagina.

\section{LONGITUDINAL VAGINAL SEPTUM}

A Longitudinal vaginal septum is found most frequently in women with septate or didelphys uterus with two 
cervices $^{8}$.Usually associated with infertility and miscarriages ${ }^{9}$. Often asymptomatic and detected incidentally during routine examination or during delivery. The diagnosis is usually missed unless careful examination is done. It may cause difficulty in inserting tompoons, persistent bleeding despite the presence of a tampoon , dyspareunia, dystocia during delivery, hygiene problems indicating the need for excision of the septum.

Some patients have unilateral obstruction and may produce hematocolpos and hematometra. They are associated with renal agenesis usually in cases of didelphys or septate uterus .Even though these patients are referred to specialists for miscarriages and infertility, the longitudinal septum per se is not the cause of infertility. There will be other uterine or hormonal reasons.

Treatment involves complete excision of the septum with care being taken to avoid causing bladder or rectal injury. Tissue should be completely excised to prevent dyspareunia. The septal tissue is resected and normal vaginal mucosa on each vaginal wall is sutured together along the length of defect made by the resection. Surgery is not necessary in asymptomatic women with longitudinal vaginal septum, however carrying out the procedure will certainly facilitate a subsequent vaginal delivery ${ }^{7}$.

\section{Case Details}

We present our case series of 8 cases who underwent excision of septum with good surgical outcomes, no vaginal restenosis and no reoperation.

All five cases of transverse vaginal septum were in the age group of 14 to 20 years, presented with various complaints like primary amenorrhea, cyclical lower abdominal pain, dysmenorrhea, dyspareunia. Local examination revealed normal vulva , introitus and normal opening of urethra. On Per speculum examination cervix was not visualized. On pelvic examination there was intervening soft tissue between urethra and rectum suggestive of vaginal septum . Ultrasonography revealed a normal uterus and cervix with transverse vaginal septum.

All cases were operated by complete surgical excision. Hematocolpos completely drained and cut edges of vaginal mucosa repaired with3-0 vicryl interrupted suture.

All these five women had a good post operative recovery following which they had normal sexual life and menstrual cycles. They conceived and had children varying from one to three.

All three cases of longitudinal vaginal septum were in the age group of 19 to 30 years, presented with various complaints like dysmenorrhea, dyspareunia, infertility and miscarriages.

Examination showed presence of longitudinal vaginal septum dividing vagina into two cavities with two cervices. Ultrasonography showed divergent uterine fundus with two separate endometrial cavities with two separate cervices. Hysterosalpingogram done cannulating each cervix separately showing two separate endometrial cavities with two cervices without any communication.MRI pelvis suggestive of widely divergent uterine horns with two separate endometrial cavities in continuity with two separate cervical canals with hypointense longitudinal septum noted in vagina.

Complete excision of vaginal septum was done taking precautions to avoid injury to bladder and rectum. Histopathology Sections show vaginal septum lined by thickened stratified squamous epithelium showing parakeratosis . Stroma shows fibromuscular tissue with many proliferated congested capillaries . No evidence of dysplasia / malignancy.

Symptoms were relieved in all these cases. First patient was delivered live child through normal vaginal delivery one year after surgical correction. Second patient was delivered a live male child by LSCS one year 3 months after surgery. Third patient has not conceived yet and is taking hormonal treatment.

\begin{tabular}{|c|c|c|c|}
\hline NO & $\overline{A G E}$ & COMPLAINT & TYPE OF SEPTUM \\
\hline \begin{tabular}{|l|}
1 \\
\end{tabular} & $\begin{array}{l}\text { FEMALE/22 } \\
\text { YRS } \\
\text { (Figure 1) }\end{array}$ & $\begin{array}{l}\text { PRIMARY } \\
\text { AMENORRHOEA } \\
\text { pain lower } \\
\text { abdomen and } \\
\text { pelvis }\end{array}$ & $\begin{array}{l}\text { MID TRANSVERSE } \\
\text { TOTAL }\end{array}$ \\
\hline 2 & $\begin{array}{l}\text { FEMALE/20 } \\
\text { YRS }\end{array}$ & $\begin{array}{l}\text { PRIMARY } \\
\text { AMENORRHOEA } \\
\text { pain lower } \\
\text { abdomen and } \\
\text { pelvis }\end{array}$ & $\begin{array}{l}\text { HIGH TRANSVERSE } \\
\text { TOTAL }\end{array}$ \\
\hline 3 & $\begin{array}{l}\text { FEMALE/14 } \\
\text { YRS } \\
\text { (Figure 2) }\end{array}$ & $\begin{array}{l}\text { PRIMARY } \\
\text { AMENORRHOEA } \\
\text { CYCLICAL PAIN } \\
\text { LOWER } \\
\text { ABDOMEN }\end{array}$ & $\begin{array}{l}\text { MIDTRANSVERSE } \\
\text { TOTAL }\end{array}$ \\
\hline 4 & $\begin{array}{l}\text { FEMALE/20 } \\
\text { YRS } \\
\text { (Figure 3) }\end{array}$ & $\begin{array}{l}\text { DYSMENORRHOE } \\
\text { A } \\
\text { DYSPAREUNIA }\end{array}$ & $\begin{array}{l}\text { LOW PARTIAL } \\
\text { TRANSVERSE }\end{array}$ \\
\hline 5 & $\begin{array}{l}\text { FEMALE/20 } \\
\text { YRS }\end{array}$ & $\begin{array}{l}\text { PRIMARY } \\
\text { AMENORRHOEA, } \\
\text { Dyspareunia }\end{array}$ & $\begin{array}{l}\text { LOW PARTIAL } \\
\text { TRANSVERSE }\end{array}$ \\
\hline 6 & $\begin{array}{l}\text { FEMALE/19 } \\
\text { YRS } \\
\text { (Figure 4) }\end{array}$ & $\begin{array}{l}\text { ABORTION, } \\
\text { MISCARRIAGE }\end{array}$ & $\begin{array}{l}\text { LONGITUDINAL } \\
\text { COMPLETE } \\
\text { DIDELPHYS } \\
\text { UTERUS }\end{array}$ \\
\hline 7 & $\begin{array}{l}\text { FEMALE/24 } \\
\text { YRS } \\
\text { (Figure 5) }\end{array}$ & INFERTILITY & $\begin{array}{l}\text { LONGITUDINAL } \\
\text { COMPLETE } \\
\text { DIDELPHYS } \\
\text { UTERUS }\end{array}$ \\
\hline 8 & $\begin{array}{l}\text { FEMALE/30 } \\
\text { YRS } \\
\text { (Figure 6) }\end{array}$ & INFERTILITY & $\begin{array}{l}\text { LONGITUDINAL - } \\
\text { COMPLETE } \\
\text { DIDELPHYS } \\
\text { UTERUS }\end{array}$ \\
\hline
\end{tabular}

\section{PHOTOGRAPHS}

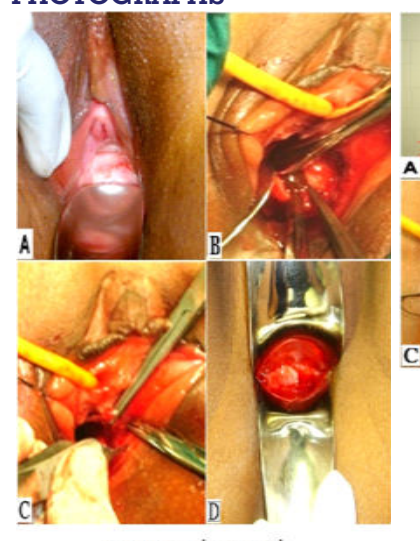

FIGURE1 $(A, B, C, D)$

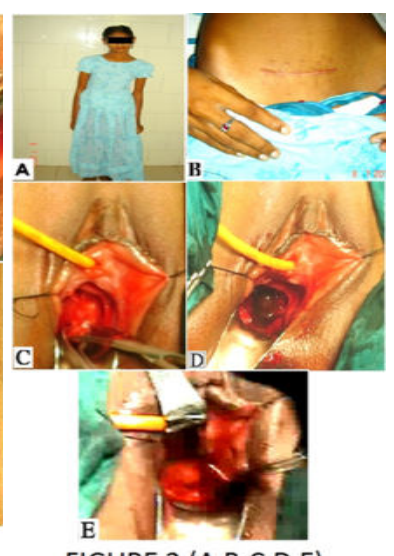

FIGURE 2 (A,B,C,D,E)
FIGURE - 1; 1 A : Preop mid horizontal vaginal septum. $1 B$ : Septum dissection opened and excised. Hematocolpos drained. 1C : Repair of vaginal mucosa all around., 1D : Postop 6 weeks. Normal vagina and cervix visualized.

FIGURE 2 ; $2 A$ : Adolescent of 14 years, Not attained menses . $2 B$ : She was operated for acute appendicitis mistakenly based on USG report. Appendix was normal . 2C : High transverse vaginal septum. 2D : Septum excised and mucosa repaired. Hematocolpos drained . 2E : Post op 6 weeks . Normal vagina with cervix visualized. 


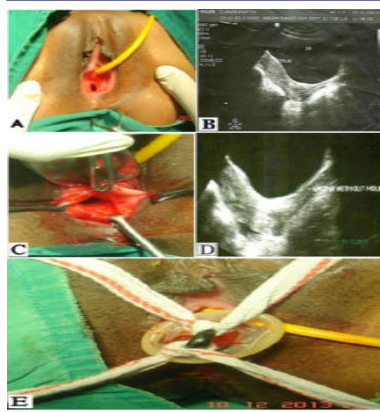

FIGURE $3(A, B, C, D, E)$

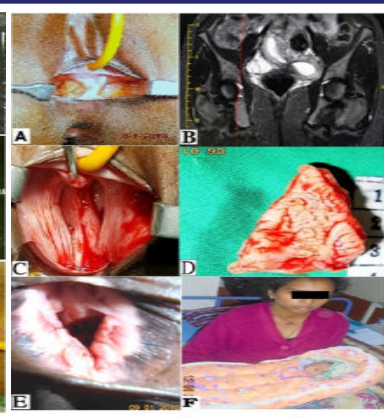

FIGURE $4(A, B, C, D, E, F)$
FIGURE - 3: 3A: Pre op low horizontal vaginal septum operated elsewhere - Incomplete . 3B : Ultrasound showing narrowing of vaginal canal. 3C: Septum completely excised and mucosa repaired. 3D : Ultrasound post op showing normal vaginal dimensions $3 \mathrm{E}$ : Soft changeable mould kept in the vagina for 2 weeks to prevent narrowing of vagina.

FIGURE4; 4A : Pre op Complete longitudinal vaginal septum. 4B : MRI pelvis showing didelphys uterus with 2 cervices. $4 \mathrm{C}$ : Complete excision of septum and repair. 4D : Excised septum [ Gross ]. 4E : Post op vaginal cavity. 4F : Delivered FTND with one year after surgery.
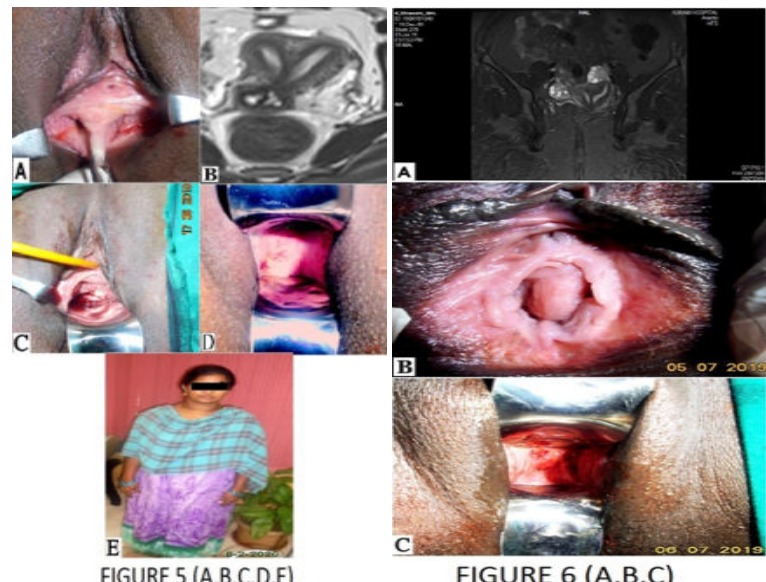

FIGURE $6(A, B, C)$

Figure 5: 5A: Pre op cervical longitudinal vaginal septum. 5B: MRI pelvis showing uterine didelphys with two cervices. 5C: Excision of septum with repair of vaginal mucosa. 5D: Postop 3 weeks showing two cervices separately. 5E: Patient was pegnant and delivered a male child 1 year 3 months after surgery

Figure 6 : 6A: MRI pelvis showing didelphius uterus with two cervices and a vagina divided longitudinally, 6B: Complete longitudinal vaginal septum.The septum is thick when compared to previous two cases,6C: After complete excision of septum

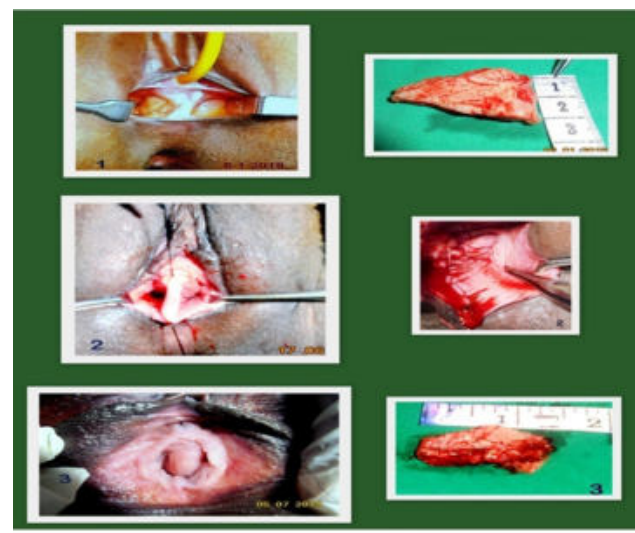

FIGURE $7(1,2,3)$

Figure 7 - Preop 1,2,3 longitudinal vaginal septa and their gross specimens of excised septa. Histopatology of all excised septa was normal.

\section{DISCUSSION}

Although a rare condition longitudinal vaginal septum should always be taken into consideration in differential diagnosis when varying combination of dysmenorrhea, menstrual blood that leaks out despite using tampoon, abnormal uterine bleeding, dyspareunia.

The principal tools for diagnosing longitudinal vaginal septum are clinical examination. Ultrasonography, Magnetic resonance imaging(MRI) and hysterosalpingography are recommended to establish the site and thickness of septum in addition to alerting to the coexistence of other associated congenital defects ${ }^{10}$. In presence of two cervices and vaginal septum the condition can be easily diagnosed on speculum or vaginal examination. Patients with longitudinal vaginal septum in case 6, one uterine hemicorpus was better developed than the other. Intercourse generally occurs on the vaginal side connected to better developed hemicorpus. If intercourse occurs on the other side repeated abortions or infertility may result.Here this patient with didelphys uterus had two miscarriages earlier and had normal vaginal delivery one year after surgical correction.

In patients with high transverse vaginal septum only a small portion of vagina is present and retrograde menstruation occurs early after onset of menstruation and may predispose to development of endometriosis ${ }^{11}$ which could well explain the reduced fertility in them.

Thus prompt diagnosis and surgical correction to drain accumulated blood may preserve reproductive capacity by preventing this sequele ${ }^{12 .}$ Diagnosis and treatment should be timely in order to avoid possible complications such as pelvic adhesions and damage to Fallopian tubes especially in cases of complete obstruction, as well as discomfort and psychological repurcussions of painful symptoms such as dyspareunia. The main differential diagnosis are vaginal agenesis and imperforate hymen.

Rareness and diversity of clinical presentation of vaginal obstructing lesions may lead to misdiagnosis . The patient might refer to different medical and surgical specialists as happened in case 3. So knowing the symptoms is necessary for its early diagnosis. As we observed in case 3 the probability of vaginal obstructing lesions in peripubertal girls with lower tract symptoms should always be considered.

Literature recommends surgery in all cases of Longitudinal vaginal septum and also suggests that resection must be performed early in cases of complete septum. Excision is the procedure of choice for treatment of longitudinal vaginal septum $^{13}$, taking care not to injure the rectum or bladder Although it is not obligatory in asymptomatic women with LVS, surgery should be performed whenever women wishes to become pregnant inorder to facilitate a subsequent normal delivery .

Complete transverse septum presents with symptoms of vaginal obstruction which occurs at the time of menarche since menstrual blood gets trapped above the septum. Imperforate vaginal septum results in primary amennorehoea, cryptomennorhoea with abdominal mass, cyclic pelvic pain, dysmenorrhea, dyspareunia. An incomplete septum which allows vaginal secretions and menstrual blood flow from vagina and hence is asymptomatic does not require correction during childhood or adolescence.So in incomplete vaginal septum, menstrual symptoms are absent and may be detected due to other presentations like dyspareunia ,obstructed vaginal delivery . It requires surgical excision of 
fibrotic tissue when patient complains of infertility or dyspareunia.Careful clinical examination and ultrasound are usually sufficient for diagnosis. MRI is needed in unclear cases like thick and high vaginal septum.

Preoperative assessment of transverse vaginal septum includes elicitation of menstrual history and performance of physical examination. Family history of genetic abnormalities, secondary sexual characters, presence of pelvic mass, appearance of internal and external genitalia should be noted. MRI is the standard for imaging Müllerian duct anomalies ${ }^{14}$. It provides high resolution images of uterine body , fundus and internal structures .Differential diagnosis of transverse vaginal septum include imperforate hymen, cervical dysgenesis and vaginal agenesis. The most common is imperforate hymen which accounts for the commonest anomaly of the vaginal outflow tract with an incidence of $l$ in 1000 women. Clinically vaginal septum is located in upper $1 / 3$ and lower $1 / 3$ of vagina while imperforate hymenal membrane is present between labia across the vaginal vestibule. Restenosis and reaccumulation of fluid in transverse vaginal septum is more common than imperforate hymen so one needs to make proper differentiation between two entities. Treatment of septum is surgical.

An important factor that influences surgical management and outcomes is the thickness of transverse vaginal septum ${ }^{15}$ as it is reported that low, thin and perforate septae due to less complexity can be treated by transvaginal resection with minimal complications.

\section{OBLIQUE VAGINAL SEPTUM}

Herlyn-werner-wunderlich syndrome includes incomplete longitudinal septum, uterine didelphys, hematocolpos, ipsilateral renal agenesis ${ }^{16}$.

\section{CONCLUSION}

Rare congenital anomalies of transverse vaginal septum can present in any age group with a wide range of clinical findings and a high index of suspicion is needed for appropriate diagnosis and adequate work up. Longitudinal vaginal septum is less common, mostly asymptomatic and detected incidentally during routine examination or during delivery and causes miscarriages and abortions and may be responsible for infertility. This anomaly is most commonly found in patients with didelphys, bicornuate and septate uterus. Whenever female in Premenarchal age presents with cyclic pelvic pain and Tenderness, a possibility of transverse vaginal septum should always be borne in mind. Ultrasound aids in localisation and characterisation of the lesion while MRI will help in confirming the vaginal septum including its thickness and relation to the adjacent structures because of its better delineation.

\section{Acknowledgment :}

Department of anesthesiology, Department of radiology, Department of pathology, ASRAM medical college.

\section{REFERENCES:}

1. Sajjad Y. Development of the genital ducts and external genitalia in the early human embryo. Journal of Obstetrics and Gynaecology Research. 2010 Oct;36(5):929-37.

2. Robboy SJ, Kurita T, Baskin L, Cunha GR. New insights into human female reproductive tract development. Differentiation. 2017 Sep 1;97:9-22.

3. Al-Salem AH. Vaginal Atresia, Agenesis and Vaginal Septum. InPediatric Gynecology 2020 (pp. 181-216). Springer, Cham.

4. Mate P. Role of Endoscopy in Vaginal Septum. Mastering the Techniques in Hysteroscopy. 2017 Mar 31:310.

5. Samal R, Hbebullah S. Primary amenorrea: a clinical review. Int J Reprod Contracept Obstet Gynecol. 2017;6:4748-53.

6. Agarwal M, Tiwary B, Gurung P. Complex mullarian duct abnormality in a young female: $\alpha$ theraputic dilemma. International Journal of Reproduction, Contraception, Obstetrics and Gynecology.; 6(8):3674.

7. Ahmadi F, Pahlavan F. A case report of didelphys uterus with right obstruction of cervix due to transverse vaginal septum. The Iranian Journal of Obstetrics, Gynecology and Infertility. 2020;23(6):110-4

8. Heinonen PK. Longitudinal vaginal septum. European Journal of Obstetrics \&
Gynecology and Reproductive Biology. 1982 Jun 1;13(4):253-8

9. Khera P Garg K, Mantri L. Complete Uterine Septum with Double Cervix and Double Vagina. Indian Journal of Gynaecological Endoscopy. 2019 Aug:28.

10. de França Neto AH, Nóbrega BV, Clementino Filho J, do Ó TC, de Amorim MM. Intrapartum diagnosis and treatment of longitudinal vaginal septum. Case reports in obstetrics and gynecology. 2014 Jan 1;2014.

11. Deligeoroglou E, Iavazzo C, Sofoudis C, Kalampokas T Creatsas G. Management of hematocolpos in adolescents with transverse vaginal septum. Archives of gynecology and obstetrics. 2012 Apr 1;285(4):1083-7.

12. Paudel R, Dangal G, Karki A, Pradhan H, Shrestha R, Bhattachan K, Bajracharya N. Primary Amenorrhoea with Transverse Vaginal Septum Presented with Infected Pyometra of 24 Weeks Size. Nepal Journal of Obstetrics and Gynaecology. 2017;12(1):66-8.

13. de França Neto AH, Nóbrega BV, Clementino Filho J, do Ó TC, de Amorim MM Intrapartum diagnosis and treatment of longitudinal vaginal septum. Case reports in obstetrics and gynecology. 2014 Jan 1;2014.

14. Deutch TD, Abuhamad AZ. The role of 3-dimensional ultrasonography and magnetic resonance imaging in the diagnosis of Müllerian duct anomalies: $a$ review of the literature. Journal of Ultrasound in Medicine. 2008 Mar;27(3):413-23.

15. Saeed SA, Masroor I, Naz S, Bhurgri S. Transverse vaginal septum: Report of two patients with MRI findings. Journal of the College of Physicians and Surgeons--Pakistan. 2017;27(9):S74

16. Orazi C, Lucchetti MC, Schingo PM, Marchetti P, Ferro F. Herlyn-WernerWunderlich syndrome: uterus didelphys, blind hemivagina and ipsilateral renal agenesis. Sonographic and MR findings in 11 cases. Pediatric radiology. 2007 Jul 1;37(7):657-65. 